\title{
Comparison of propofol-dexmedetomidine, tiopental-dexmedeto- midine and etomidate-dexmedetomidine combinations' effects on the tracheal intubation conditions without using muscle relaxants
}

\author{
Bollucuoglu K, Hanci V, Yurtlu S, Okyay D, Ayoglu H, Turan IO \\ Zonguldak Karaelmas University, School of Medicine, Department of Anesthesiology and Reanimation, \\ Zonguldak, Turkey. vhanci@gmail.com
}

\begin{abstract}
Background: In our study, we aimed to compare the endotracheal intubation conditions without muscle relaxants during induction with the combinations of dexmedotimidine-propofol, dexmedotimidine-thiopenthal and dexmedetomidine-etomidate.

Method: Seventy-six patients, in ASA risk group I-II, between ages 20-60 years, with Mallampati Class 1 were included in the study. All patients were premedicated with midazolam. The patients were randomly divided into three groups as Group P ( $n=30$, dexmedetomidine-propofol), Group T ( $n=30$, dexmedetomidine-thiopenthal), Group $\mathrm{E}$ ( $\mathrm{n}=16$, dexmedetomidine-etomidate). All patients received dexmedetomidine $1 \mu \mathrm{g} \cdot \mathrm{kg}^{-1}$ in $10 \mathrm{~min}$. Then, the patients were administered $2.5 \mathrm{mg} \cdot \mathrm{kg}^{-1}$ propofol for Group P, $5 \mathrm{mg} \cdot \mathrm{kg}^{-1}$ thiopental for Group T and $0.3 \mathrm{mg} \cdot \mathrm{kg}^{-1}$ etomidate for Group $\mathrm{E}$ during induction. Hemodynamic data of the patients were recorded before induction, after dexmedetomidine administration, immediately after intubation and 3, 5 and 10 minutes after intubation. Results: There was no difference between the groups according to hemodynamic data. Sixteen patients in Group $\mathrm{P}$ and 10 patients in Group T had acceptable intubation conditions. Muscle relaxant was needed in 14, 20 and 16 patients in Groups P, T and E, respectively $(p<0.05)$.

Conclusion: In conclusion, we determined that best intubation conditions without muscle relaxants were achieved with propofol-dexmedetomidine combination. None of the patients receiving etomidate -dexmedetomidine combination could be intubated without muscle relaxants (Tab. 6, Ref. 29). Full Text in PDF www.elis.sk.

Key words: intubation without muscle relaxants, propofol, thiopental, etomidate, dexmedetomidine.
\end{abstract}

General anesthesia is commonly induced by using endotracheal intubation (1). Muscle relaxants are frequently used to facilitate endotracheal intubation during induction of anesthesia $(2,3,4)$. However, the administration of short-acting depolarizing muscle relaxants is closely related to postoperative myalgias, malignant hyperthermia, hyperkalemia, and increased intracranial or intraocular pressure. The use of non-depolarizing muscle relaxants may produce a prolonged neuromuscular blockade, potentiate the histamine release, increase the side effects from anticholinesterases used for the reversal of agents, and lead to an inability to quickly reverse the blockade in an event of unexpected difficult intubation (3-8). When the use of muscle relaxants is undesirable or contraindicated, the administration of proper induction agents to provide good intubating conditions without using muscle relaxants is an important issue (3-7).

Dexmedetomidine is a highly selective alpha- 2 agonist with analgesic and sedative effects but does not cause respiratory depression (2, 9-11). In combination with propofol, dexmedetomidine has been demonstrated to assist in extubation, fiberoptic intu-

Zonguldak Karaelmas University, School of Medicine, Department of Anesthesiology and Reanimation, Zonguldak, Turkey

Address for correspondence: V. Hanci, MD, Tepebasi Mahallesi, Yapkent sokak, Kale Sitesi A13 Blok, Daire:10, Zonguldak, Turkey.

Phone: +90.505 .6806053$ bation, awake blind nasotracheal intubation, LMA placement and intubation without muscle relaxants (2,9-16). However there is no information on dexmedetomidine combined with other intravenous induction agents such as thiopental and etomidate, for laryngoscopic endotracheal intubation in the absence of muscle relaxants.

We have hypothesized that propofol provides better intubation conditions than other induction agents in the absence of muscle relaxants.

Therefore, the aim of this study was to investigate the efficiency of dexmedetomidine-propofol, dexmedetomidine-thiopental and dexmedetomidine-etomidate combinations for laryngoscopic endotracheal intubation in absence of muscle relaxants.

\section{Methods}

Ethics

Ethical approval for this study (Ethical Committee No. 2009/08-75) was provided by the Ethical Committee of Karaelmas University Hospitals, Zonguldak, Turkey (President Assoc. Prof. BD. Gun) on 23 June 2009.

After obtaining the approval of hospital ethics committee and obtaining the patient informed consent, a total of 76 patients were enrolled in the study. All patients were in the ASA I risk group, aged between 18 and 59 years, hospitalized for elective surgery under general anesthesia with no history of drug or alcohol abuse, dif- 
Tab. 1. Intubating condition score (4).

\begin{tabular}{lcccc}
\hline Variable & \multicolumn{4}{c}{ Score } \\
\cline { 2 - 5 } & 1 & 2 & 3 & 4 \\
\hline Mask ventilation & Easy & Difficult & Impossible & - \\
Jaw relaxation & Complete & Slight tone & Stiff & Rigid \\
Laryngoscopy & Easy & Fair & Difficult & Impossible \\
Vocal cord position & Open & Moving & Closing & Closed \\
Coughing & None & Slight & Moderate & Severe \\
Limb movement & None & Slight & Moderate & Severe \\
Cuff response & None & Slight & Moderate & Severe \\
\hline
\end{tabular}

ficult intubations or cardiovascular and cerebrovascular diseases. They were all Mallampati class I and their body mass index was less than 30. Patients were randomized into three groups using a random samples table.

Forty-five minutes prior to induction, all patients were premedicated with intramuscular $0.07 \mathrm{mg} . \mathrm{kg}^{-1}$ midazolam. In the operation room, a 20-gauge cannula was used for intravenous access, and 7-10 mL. $\mathrm{kg}^{-1}$ Ringer's Lactate was administered.

The baseline arterial blood pressure, peripheral oxygen saturation, ECG and end-tidal $\mathrm{CO}_{2}$ measurements of the patients were obtained with standard monitoring. Then, all patients received $1 \mu \mathrm{g} . \mathrm{kg}^{-1}$ dexmedetomidine (Precedex ${ }^{\circledR}, 100 \mu \mathrm{g} \cdot \mathrm{mL}^{-1}$, Hospira, USA) diluted to a total volume of $10 \mathrm{~mL}$ and infused within 10 minutes using a calibrated electronic infusion pump (Braun Infusomat $^{\mathbb{R}}$; Braun Melsungen Ko, Germany). Preoxygenation was started in last 3 minutes within dexmedetomidine infusion. After the administration of dexmedetomidine, the patients received 2.5 mg. $\mathrm{kg}^{-1}$ propofol in Group $\mathrm{P}(\mathrm{n}=30), 5 \mathrm{mg} \cdot \mathrm{kg}^{-1}$ thiopental in Group $\mathrm{T}(\mathrm{n}=30)$, and $0.3 \mathrm{mg} \cdot \mathrm{kg}^{-1}$ etomidate in Group E over 30 seconds.

After the loss of consciousness, mask ventilation was initiated. Mask ventilation was assessed in all patients with a 3-point scoring system (1: adequate, 2: difficult but possible, 3: not possible). Until intubation, mask ventilation was maintained for 90 seconds. For all patients, intubation was performed by the same anesthesiologist, who had not been informed about the drug being used, using a Macintosh 3 laryngoscope blade and an $8.0 \mathrm{~mm}$ endotracheal tube (ETT) for males and $7.5 \mathrm{~mm}$ ETT for females. Following the tracheal intubation, the ETT cuff (ETTc) was gently inflated using an analogue manometer (VBM Medizintechnik $^{\circledR}, \mathrm{GmbH}$, Germany) to between $20-25 \mathrm{cmH}_{2} \mathrm{O}$ in all patients. Intubation conditions in all patients were assessed by the scoring system shown in Table 1 (4).

According to these criteria, intubation conditions were "excellent" (all criteria achieved score 1), "good" (mask ventilation achieved score 1, and the other criteria 1 or 2), "poor" (one of the criteria achieved score 3 ) and "inadequate" (one of the criteria finished with score 4) (4).
Should one of the criteria achieve score 4 in the assessment or the endotracheal intubation be unsuccessful on first attempt, the patients received $0.6 \mathrm{mg} . \mathrm{kg}^{-1}$ rocuronium and were recorded. Complications during intubation, such as coughing, laryngospasm, bronchospasm were also recorded.

Patients' heart rate (HR), systolic arterial pressure (SAP), mean arterial pressure (MAP) and $\mathrm{SpO}_{2}$ were recorded at each checkpoint, including prior to induction, after dexmedetomidine, at induction drug administration, at endotracheal intubation, and 3 and 5 minutes after intubation. The rate pressure product (RPP), which is calculated by the following formula: RPP $=$ HR X SAP, was calculated for each measurement time and recorded in every patient.

Atropine $0.5 \mathrm{mg}$ could be administered for bradycardia ( $\mathrm{HR}<$ 50 beats. $\mathrm{min}^{-1}$ ). Should mean arterial blood pressure decrease below $30 \%$ of the control value for a minimum of 60 seconds, $5 \mathrm{mg}$ ephedrine was planned to be administered (2).

After intubation, anesthesia was maintained in all patients with $66 \%$ nitrous oxide in oxygen and $0.5 \%$ sevoflurane. Patients were ventilated with end-tidal $\mathrm{CO}_{2}$ values of $35-40 \mathrm{mmHg}$. During the study, any of surgical painful stimuli were avoided.

\section{Power analysis}

In our previous report using a combination of dexmedetomidine and propofol for tracheal intubation without muscle relaxant, the incidence of poor and inadequate intubation condition was approximately $6.7 \%$ (2). Based on these data and in order to detect an absolute difference of $25 \%$ between the proportions of poor and inadequate intubating conditions with $80 \%$ power and a 0.05 level of significance, 30 patients were required in each group.

\section{Statistical analysis}

The data were analyzed using Statistical Package for the Social Sciences (SPSS) 15.0. Descriptive statistics for continuous variables are given as mean \pm standard deviation. Categorical variables are shown as percent. Analysis of distribution was performed by Kolmogorov-Smirnov test. One-way ANOVA was used for HR, MBP levels, $\mathrm{SpO}_{2}$, age, height, weight, mean intubation condition score and intubation periods; Chi-square test was used for sex, side effects, intubation condition scores and ASA physical conditions. Values of $\mathrm{p}<0.05$ were considered statistically significant.

\section{Results}

We planned a total of 90 patients to be received in our study. However, all patients in etomidate goup needed muscle relaxants for intubation; this group terminated by the decision of investigators because of ethical reasons.

Tab. 2. Demographic data of groups.

\begin{tabular}{|c|c|c|c|c|}
\hline & Group P $(n=30)$ & Group T $(n=30)$ & Group E $(n=16)$ & $\mathrm{p}$ \\
\hline Age (year) (mean \pm SD) & $38.4 \pm 10.9$ & $35.9 \pm 10.7$ & $34.1 \pm 9.3$ & 0.402 \\
\hline Height $(\mathrm{cm})($ mean \pm SD $)$ & $166 \pm 10.3$ & $167.5 \pm 8.3$ & $167.8 \pm 7.7$ & 0.730 \\
\hline Weight $(\mathrm{kg})($ mean $\pm \mathrm{SD})$ & $68.7 \pm 12.8$ & $68.8 \pm 9$ & $69.1 \pm 10.6$ & 0.999 \\
\hline BMI (Ort \pm SS) & $24.7 \pm 2.4$ & $24.5 \pm 2.8$ & $24.4 \pm 2.3$ & 0.934 \\
\hline ASA (I/II), (n,\%) & $22(\% 73.3) / 8(\% 26.7)$ & $26(\% 86.7) / 4(\% 13.3)$ & 13(\%81.2)/3(\%18.8) & 0.426 \\
\hline $\operatorname{Sex}(M / F)(n)$ & $20(\% 66.7) / 10(\% 33.3)$ & $18(\% 60) / 12(\% 40)$ & $8(\% 50) / 8(\% 50)$ & 0.544 \\
\hline
\end{tabular}


Tab. 3. Heart rate changes in groups (mean $\pm \mathrm{SD})$.

\begin{tabular}{lccc}
\hline & $\begin{array}{c}\text { Grup P } \\
(\mathrm{n}=30)\end{array}$ & $\begin{array}{c}\text { Grup T } \\
(\mathrm{n}=30)\end{array}$ & $\begin{array}{c}\text { Grup E } \\
(\mathrm{n}=16)\end{array}$ \\
\hline Control & $83.33 \pm 13.97$ & $76.47 \pm 11.68$ & $76.88 \pm 9.50$ \\
After Dexmedetomidine & $65.70 \pm 10.40$ & $67.73 \pm 12.49$ & $68.62 \pm 9.43$ \\
After Study Drugs & $68.77 \pm 9.07$ & $75.50 \pm 10.01$ & $70.19 \pm 8.90$ \\
After Intubation 0.min & $82.40 \pm 10.96$ & $86.17 \pm 11.54$ & $82.62 \pm 12.53$ \\
After Intubation 3.min & $77.80 \pm 9.93$ & $80.43 \pm 9.89$ & $76.88 \pm 9.94$ \\
After Intubation 5.min & $76.33 \pm 9.79$ & $79.27 \pm 10.04$ & $75.50 \pm 8.48$ \\
After Intubation 10.min & $74.03 \pm 9.22$ & $77.20 \pm 8.98$ & $72.81 \pm 8.81$
\end{tabular}

Tab. 4. Mean arterial pressure changes in groups (mean $\pm \mathrm{SD})$.

\begin{tabular}{lccc}
\hline & $\begin{array}{c}\text { Grup P } \\
(\mathrm{n}=30)\end{array}$ & $\begin{array}{c}\text { Grup T } \\
(\mathrm{n}=30)\end{array}$ & $\begin{array}{c}\text { Grup E } \\
(\mathrm{n}=16)\end{array}$ \\
\hline Control & $95.83 \pm 7.94$ & $91.50 \pm 11.07$ & $90.94 \pm 7.64$ \\
After Dexmedetomidine & $89.90 \pm 9.98$ & $85.60 \pm 9.66$ & $86.50 \pm 8.36$ \\
After Study Drugs & $82.60 \pm 9.05$ & $84.43 \pm 12.64$ & $86.87 \pm 13.38$ \\
After Intubation 0.min & $96.90 \pm 13.97$ & $100.70 \pm 15.08$ & $103.13 \pm 11.48$ \\
After Intubation 3.min & $87.07 \pm 10.4$ & $88.47 \pm 11.85$ & $92.0 \pm 10.07$ \\
After Intubation 5.min & $79.03 \pm 8.84$ & $79.80 \pm 10.12$ & $86.69 \pm 12.39$ \\
After Intubation 10.min & $78.97 \pm 10.27$ & $78.40 \pm 10.69$ & $84.69 \pm 12.41$ \\
\hline & & &
\end{tabular}

There was no difference between the demographic data, heart rate, mean arterial pressure, $\mathrm{RPP} \mathrm{EtCO}_{2}$ and $\mathrm{SpO}_{2}$ values of the study groups (Tabs 2-5).

One patient in Group P and two patients in Group $\mathrm{T}$ required atropine, whereas no patient needed it in Group E. The difference was not significant $(\mathrm{p}=0.529)$. None of the patients in either group required ephedrine.

When intubation conditions were assessed, the response of laryngoscopy $(\mathrm{p}<0.001)$, position of the vocal cords during intubation $(\mathrm{p}=0.011)$, and limb movement of the endotracheal intubation $(p=0.044)$ were statistically significant between groups. The intubation condition score based on all criteria ( $\mathrm{p}=0.003)$, and muscle relaxant requirement $(\mathrm{p}=0.001)$ were also statistically significant between groups (Tab. 6).

None of patients had laryngospasm or bronchospasm.

\section{Discussion}

In this study, propofol-dexmedetomidine and thiopental-dexmedetomidine combinations provided better intubation conditions when administered without muscle relaxants than the etomidatedexmedetomidine combination.

Dexmedetomidine is a highly selective alpha-2 agonist with analgesic and sedative effects $(2,9,10,14,16)$. Dexmedetomidine use is becoming increasingly popular in both general and regional anesthesia $(2,17,18)$. Previous case reports and case series have
Tab. 6. Intubation condition score data of groups.

\begin{tabular}{|c|c|c|c|c|}
\hline & Group P & Group T & Group E & $\mathrm{p}$ \\
\hline Mask Ventilation, $\mathrm{n}$ & 30 & 30 & 16 & 1 \\
\hline Easy $(n, \%)$ & $30(100 \%)$ & $30(100 \%)$ & $16(100 \%)$ & \\
\hline Jaw Relaxation,n & 30 & 30 & 16 & 0.999 \\
\hline Complete (n,\%) & $25(83.3 \%)$ & $25(83.3 \%)$ & $13(81.2 \%)$ & \\
\hline Slight tone $(\mathrm{n}, \%)$ & $3(10 \%)$ & $3(10 \%)$ & $2(12.5 \%)$ & \\
\hline Stiff $(n, \%)$ & $2(6.7 \%)$ & $2(6.7 \%)$ & $1(6.2 \%)$ & \\
\hline Laryngoscopy*†, n & 30 & 30 & 16 & $<0.001$ \\
\hline Easy & $24(80 \%)$ & $20(66.7 \%)$ & $2(12.5 \%)$ & \\
\hline Fair & $4(13.3 \%)$ & $8(26.7 \%)$ & - & \\
\hline Difficult & $1(\% 3.3)$ & $2(6.7 \%)$ & $10(62.5 \%)$ & \\
\hline Impossible & $1(\% 3.3)$ & - & $4(25 \%)$ & \\
\hline Vocal Cord Position*, $n$ & 29 & 30 & 12 & 0.011 \\
\hline Open $(\mathrm{n}, \%)$ & $11(37.9 \%)$ & $4(13.3 \%)$ & - & \\
\hline Moving (n,\%) & $7(24.1 \%)$ & $4(13.3 \%)$ & $2(16.7 \%)$ & \\
\hline Closing (n,\%) & $2(6.9 \%)$ & $4(13.3 \%)$ & & \\
\hline Closed & $9(31 \%)$ & $18(60 \%)$ & $10(83.3 \%)$ & \\
\hline Coughing, $\mathrm{n}$ & 20 & 12 & 2 & 0.073 \\
\hline None & $3(15 \%)$ & $2(16.7 \%)$ & - & \\
\hline Slight & $12(60 \%)$ & $4(33.3 \%)$ & - & \\
\hline Moderate & $5(25 \%)$ & $3(25 \%)$ & $2(\% 100)$ & \\
\hline Severe & - & $3(25 \%)$ & - & \\
\hline Limb movement $\dagger, \mathrm{n}$ & 20 & 9 & 2 & 0.044 \\
\hline None & $6(30 \%)$ & $1(11.1 \%)$ & - & \\
\hline Slight & $7(35 \%)$ & $5(55.6 \%)$ & - & \\
\hline Moderate & $3(15 \%)$ & $3(33.3 \%)$ & - & \\
\hline Severe & $4(20 \%)$ & - & $2(100 \%)$ & \\
\hline Cuff response, $n$ & 16 & 9 & - & 0.702 \\
\hline None & $1(6.7 \%)$ & - & - & \\
\hline Slight & $11(73.3 \%)$ & $6(66.7 \%)$ & - & \\
\hline Moderate & $4(20 \%)$ & $3(33.3 \%)$ & - & \\
\hline Severe & - & - & - & \\
\hline Intubation Condition Score*, $\mathrm{n}$ & 30 & 30 & 16 & 0.003 \\
\hline Good (n, \%) & $12(40 \%)$ & $4(13.3 \%)$ & - & \\
\hline Poor $(n, \%)$ & $4(13.3 \%)$ & $5(16.7 \%)$ & - & \\
\hline Inadequate $(\mathrm{n}, \%)$ & $14(46.7 \%)$ & $21(70 \%)$ & $16(100 \%)$ & \\
\hline Muscle relaxant requirement $*_{\dagger}+$ & & & & 0.001 \\
\hline No & $16(53.3 \%)$ & $9(30 \%)$ & - & \\
\hline Yes & $14(46.7 \%)$ & $21(70 \%)$ & $16(100 \%)$ & \\
\hline
\end{tabular}

$* \mathrm{p}<0.05$; Between Group P and Group E, $\uparrow \mathrm{p}<0.05$; Between Group T and Group E

reported that when used with topical anesthetics, dexmedetomidine provides adequate sedation for awake $(14,15,16)$ and fiberoptic intubation $(9,10,12,13,19,20)$. In our previous study, we showed that intubation without muscle relaxation was possible with a dexmedetomidine, lidocaine and propofol combination (2). On the other hand, our literature analysis found no studies to evaluate the effects of combinations of dexmedetomidine with other intravenous induction agents, thiopental and etomidate, on intubation without muscle relaxation.

Tab. 5. Rate pressure product changes in groups (mean \pm SD).

\begin{tabular}{lccc}
\hline & Grup P $(\mathrm{n}=30)$ & Grup T $(\mathrm{n}=30)$ & Grup E $(\mathrm{n}=16)$ \\
\hline Control & $10190.16 \pm 1779.71$ & $9298.46 \pm 1795.07$ & $9157.87 \pm 1146.92$ \\
After Dexmedetomidine & $7667.27 \pm 1390.32$ & $7746.50 \pm 1813.70$ & $7718.31 \pm 922.44$ \\
After Study Drugs & $7277.27 \pm 1034.13$ & $8136.20 \pm 1796.20$ & $7838.56 \pm 1255.86$ \\
After Intubation 0.min & $10350.77 \pm 1896.84$ & $11299.17 \pm 2099.27$ & $10827.06 \pm 1802.08$ \\
After Intubation 3.min & $8742.47 \pm 1619.10$ & $9136.43 \pm 1545.99$ & $8875.88 \pm 1256.13$ \\
After Intubation 5.min & $8067.77 \pm 1420.19$ & $8207.70 \pm 1554.27$ & $8266.13 \pm 1385.37$ \\
After Intubation 10.min & $7726.83 \pm 1412.94$ & $7801.13 \pm 1398.32$ & $7919.00 \pm 1602.02$ \\
\hline
\end{tabular}


Previous studies have also been focused on the selection of intravenous anesthetics to be used in combination with opioids in intubation without muscle relaxation $(4,7,21)$. Güzeldemir et al (21) studied the effects of combining $50 \mu / \mathrm{kg}$ alfentanil and 2.5 $\mathrm{mg} / \mathrm{kg}$ propofol, $5 \mathrm{mg} / \mathrm{kg}$ thiopental or $0.3 \mathrm{mg} / \mathrm{kg}$ etomidate on intubation without muscle relaxation. They reported comfortable intubation in 17 patients who were administered propofol and in 13 patients who were administered thiopental. After observing $100 \%$ failure in 5 patients, the etomidate group was stopped. Similarly, in our study too, we found a statistical difference in intubation without relaxation rates in the propofol and thiopental groups, while the etomidate group was stopped after failure in all 16 patients. Güzeldemir et al (21) attributed their failure in the etomidate group to the increase in muscular tonus it caused and stated that etomidate should not be preferred in intubation without muscle relaxation.

Stevens et al (7) evaluate the effects of alfentanil and propofol, thiopental or etomidate; alfentanil lidocaine combination and propofol, thiopental or etomidate combinations on intubation without muscle relaxation, and reported adequate endotracheal intubation conditions in the propofol-alfentanil and etomidatealfentanil groups. The worst intubation conditions were achieved with the alfentanil-thiopental combination.

Erhan et al (4) evaluated the effects of $3 \mu \mathrm{g} / \mathrm{kg}$ remifentanil and $2 \mathrm{mg} / \mathrm{kg}$ propofol, $6 \mathrm{mg} / \mathrm{kg}$ thiopental and $0.3 \mathrm{mg} / \mathrm{kg}$ etomidate combination on intubation without muscle relaxation. They reported intubation success in 14 patients who were administered propofol, in 12 who were administered thiopental, and in 10 who were administered etomidate. Likewise, we did not find any statistical difference between the intubation rates in the propofol and thiopental groups; however, we concluded that the worst intubation conditions were in the etomidate group.

The differences regarding comfortable intubation found by previous studies between propofol and thiopental have been attributed to greater muscle relaxation in the upper respiratory system achieved with propofol (22-25). Mc Keating et al (23) compared the depressing effect of thiopental and propofol induction doses on airway activity, and found that a laryngoscope was easier to perform in the propofol group that was not administered muscle relaxant than in the group that received equipotent dose of thiopental. Further, they found that pharyngeal and laryngeal activities were suppressed more in the propofol group than in the thiopental group (23). Barker et al (24) evaluated vocal cord behavior following anesthesia induction with propofol and thiopental with the help of fiberoptic laryngoscope, and found more vocal cord adduction in the thiopental group than in the propofol group. The lower need for muscle relaxants that we found in the propofol group when compared to thiopental may be attributed to this reason. At the same time, we found no statistically significant difference between propofol and thiopental groups with respect to the use of muscle relaxant.

One of the most debated issues in studies comparing intravenous anesthetics used during intubation without muscle relaxation is the use of different anesthetic doses $(4,7,21)$. Various methods have been used to identify the equipotent doses of anesthetics. A study which aimed to identify the equipotent doses of propofol, thiopental and etomidate by examining consciousness loss and EEG changes reports equipotent doses of $2.5 \mathrm{mg} / \mathrm{kg}$ for propofol, $5 \mathrm{mg} / \mathrm{kg}$ for thiopental and $0.3 \mathrm{mg} / \mathrm{kg}$ for etomidate (26). We used these doses in our study. We are of the opinion that different intravenous anesthetic induction doses may have caused different combination results in different studies.

In previous studies, Hanci et al (2) used a dexmedetomidine, propofol and lidocaine combination for intubation without muscle relaxants and achieved successful intubation in all patients. In our study, intubation without muscle relaxants was possible in $53.3 \%$ of the patients in whom we used dexmedetomidine propofol combination. When used alone at a dose of $2.5 \mathrm{mg} / \mathrm{kg}$, propofol was shown to provide adequate intubation in only $20 \%$ of patients (27). In our study, $2.5 \mathrm{mg} / \mathrm{kg}$ propofol combined with dexmedetomidine provided adequate intubation in $53.3 \%$ of our patients. It was noted that Hanci et al (2) used a dose of $3 \mathrm{mg} / \mathrm{kg}$ propofol and successfully intubated all of their patients. We are of the opinion that propofol dose caused the difference in intubation without muscle relaxation in various studies. Lieutaud et al (28) concluded that a decrease in the dose of propofol would cause a significant decrease in the incidence of clinically acceptable intubating conditions.

Hanci et al (2) used lidocaine as an adjuvant in their study with the aim of suppressing the reflex response development to laryngoscopy during intubation without muscle relaxation, providing antitussive effect and preventing hypertension and tachycardia following laryngoscopy. Previous studies have reported that lidocaine reduces the severity and incidence of coughing during tracheal intubation, provides an antitussive effect, increases the depth of general anesthesia, and has an optimal dose of $1.5 \mathrm{mg} / \mathrm{kg}$ prior to intubation $(7,25,29)$. In our study we did not use lidocaine. We are of the opinion that the differences between the results of these studies may have resulted from the propofol dose, using lidocaine as an adjuvant, and the differences between the scoring systems used in the two studies.

Our study has several limitations. We have not included control groups where propofol, thiopental and etomidate were used alone. It was thought that having these control groups would not be ethical as propofol, thiopental and etomidate are all rather ineffectual in providing intubation conditions without muscle relaxation, and increasing the dose in order to achieve adequate conditions would be unsafe as it prevents the use of an equipotent dose and disrupts hemodynamic variables.

In sum, these results suggest that the propofol-dexmedetomidine combination may be preferred for anesthesia induction in cases where intubation is performed without muscle relaxation.

\section{References}

1. Hanci V, Yurtlu S, Hakimoglu S, Yilmaz M, Ayoglu H, Basaran M, Erdogan G, Okyay RD, Turan IO. The effects of the menstrual cycle on the hemodynamic response to laryngoscopy and tracheal intubation. Anesth Analg 2010, June 28.

2. Hanci V, Erdogan G, Okyay RD, Yurtlu BS, Ayoglu H, Baydilek Y, Turan IO. Effects of fentanyl-lidocaine-propofol and dexmedetomidinelidocaine-propofol on tracheal intubation without use of muscle relaxants. Kaohsiung J Med Sci 2010; 26: 244-550. 
3. Stevens JB, Wheatley L. Tracheal intubation in ambulatory surgery patients: using remifentanil and propofol without muscle relaxants. Anesth Analg 1998; 86: 45-49.

4. Erhan E, Ugur G, Gunusen I, Alper I, Ozyar B. Propofol - not thiopental or etomidate - with remifentanil provides adequate intubating conditions in the absence of neuromuscular blockade. Can J Anesth 2003; 50: $108-115$.

5. Collins L, Prentice J, Vaghadia H. Tracheal intubation of outpatients with and without muscle relaxants. Can J Anesth 2000; 47: 427-432.

6. Durmus M, Ender G, Kadir AB, Nurcin G, Erdogan O, Ersoy O. Remifentanil with thiopental for tracheal intubation without muscle relaxants. Anesth Analg 2003; 96: 1336-1339.

7. Stevens JB, Vescovo MV, Harris KC, Walker SC, Hickey R. Tracheal intubation using alfentanil and no muscle relaxant: is the choice of hypnotic important? Anesth Analg 1997; 84: 1222-1226.

8. Shields JA. Heart block and prolonged Q-Tc interval following muscle relaxant reversal: a case report. AANA J 2008; 76: 41-45.

9. Scher CS, Gitlin MC. Dexmedetomidine and low-dose ketamine provide adequate sedation for awake fibreoptic intubation. Can J Anesth 2003; 50: 607-610.

10. Jooste EH, Ohkawa S, Sun LS. Fiberoptic intubation with dexmedetomidine in two children with spinal cord impingements. Anesth Analg 2005; 101: 1248 .

11. Üzümcügil F, Canbay O, Celebi N, Karagoz AH, Ozgen S. Comparison of dexmedetomidine-propofol vs fentanyl-propofol for laryngeal mask insertion. Eur J Anaesthesiol 2008; 25: 675-680.

12. Avitsian R, Lin J, Lotto M, Ebrahim Z. Dexmedetomidine and awake fiberoptic intubation for possible cervical spine myelopathy: a clinical series. J Neurosurg Anesthesiol 2005; 17: 97-99.

13. Grant SA, Breslin DS, MacLeod DB, Gleason D, Martin G. Dexmedetomidine infusion for sedation during fiberoptic intubation: a report of three cases. J Clin Anesth 2004; 16: 124-126.

14. Maroof M, Khan RM, Jain D, Ashraf M. Dexmedetomidine is a useful adjunct for awake intubation. Can J Anesth 2005; 52: 776-777.

15. Nagashima M, Kunisawa T, Takahata O, Iwasaki H. Dexmedetomidine infusion for sedation during awake intubation. Masui 2008; 57 : 731-734.

16. Abdelmalak B, Makary L, Hoban J, Doyle DJ. Dexmedetomidine as sole sedative for awake intubation in management of the critical airway. J Clin Anesth 2007; 19: 370-373.
17. Hanci V, Erol B, Bektaş S, Mungan G, Yurtlu S, Tokgöz H, Can M, Ozkoçak Turan I. Effect of deksmedetomidine on testicular torsion/ detorsion damage in rats. Urol Int 2010; 84: 105-111.

18. Hanci V, Karakaya K, Yurtlu S, Hakimoğlu S, Can M, Ayoglu H, Erdogğan G, Okyay RD, Turan IO. Effects of dexmedetomidine pretreatment on bupivacaine cardiotoxicity in rats. Reg Anesth Pain Med 2009; 34: 565-568.

19. Bergese SD, Khabiri B, Roberts WD, Howie MB, McSweeney TD, Gerhardt MA. Dexmedetomidine for conscious sedation in difficult awake fiberoptic intubation cases. J Clin Anesth 2007; 19: 141-144.

20. Stamenkovic DM, Hassid M. Dexmedetomidine for fiberoptic intubation of a patient with severe mental retardation and atlantoaxial instability. Acta Anaesthesiol Scand 2006; 50: 1314-1315.

21. Güzeldemir ME, Dagli G, Bayhan N, Erk K, Orhan ME. Comparison of propofol, tiopental and etomidate with alfentanil and lidocaine spray for tracheal intubation conditions without use of muscle relaxants. JTAICS 1994; 22:106-108.

22. Hovorka J, Honkavaara P, Kortilla K. Tracheal intubation after induction of anesthesia with thiopental or propofol without muscle relaxants. Acta Anaesthesiol Scand 1991; 35: 326

23. McKeating K, Bali IM, Dundee JW. The effects of thiopentone and propofol on upper airway integrity. Anaesthesia 1988; 43: 638-640.

24. Barker P, Langton JA, Wilson IG, Smith G. Movements of the vocal cords on induction of anaesthesia with thiopentone or propofol. Br J Anaesth 1992; 69: 23-25.

25. Taha S, Siddik-Sayyid S, Alameddine M, Wakim C, Dahabra C, Moussa A, Khatib M, Baraka A. Propofol is superior to thiopental for intubation without muscle relaxants. Can J Anaesth 2005; 52: 249-253.

26. Kuizenga K, Wierda JMK, Kalkman CJ. Biphasic EEG changes in relation to loss of consciousness duringinduction with thiopental, propofol, etomidate, midazolamor sevoflurane. Br J Anaesth 2001; 86: 354-360.

27. Grange CS, Suresh D, Meikle R, Carter JA, Goldhill DR. Intubation with propofol: evaluation of pre-treatment with alfentanil or lignocaine. Eur J Anaesthesiol 1993; 10: 9-12.

28. Lieutaud T, Billard V, Khalaf H, Debaene B. Muscle relaxation and increasing doses of propofol improve intubating conditions. Can J Anaesth 2003; 50: 121-126.

29. Davidson JA, Gillespie JA. Tracheal intubation after induction of anaesthesia with propofol, alfentanil and i.v. lignocaine. Br J Anaesth 1993; 70: 163-166. 